\title{
Too much trade: The hidden problem of adverse selection.*
}

\author{
David de Meza $^{\dagger} \quad$ Francesco Reito $\quad$ Diane Reyniers ${ }^{\S}$
}

\begin{abstract}
Adverse selection famously leads to the crowding out of socially beneficial trades. We show that even more trades may be simultaneously crowded in. The reason is that, in the absence of complete unravelling, "lemons" fetch more under adverse selection. It is demonstrated how these "bad" trades occur in insurance, credit and used-car markets, and some policy implications are discussed.
\end{abstract}

Keywords: adverse selection, insurance, credit, used cars.

JEL classification: C13, D14, D82.

${ }^{*}$ We very much appreciate comments from Liran Einav, Amy Finkelstein, Daniel Gottlieb, Evan Saltzman, three refereees and the editor, Nathan Hendren.

${ }^{\dagger}$ London School of Economics, Houghton St, London WC2A 2AE, UK. d.de-meza@lse.ac.uk.

$\ddagger$ Department of Economics and Business, University of Catania, Italy. reito@unict.it

${ }^{\S}$ London School of Economics, Houghton St, London WC2A 2AE, UK. d.j.reyniers@lse.ac.uk 


\section{Introduction}

The seminal contribution of Akerlof (1970) shows how adverse selection leads to the crowding out of socially beneficial trades. This paper shows that adverse selection can simultaneously crowd in even more trades for which social cost exceeds social benefit. Consider Akerlof's leading example, the market for used cars. ${ }^{1}$ The assumptions imply that owners of the worst lemons would sell their vehicles under symmetric information and, if the market does not completely unravel, would also sell them under asymmetric information. ${ }^{2}$ In reality, there may be owners of lemons who would not sell their cars under symmetric information, for example because they have got used to the cars' quirks and can handle them better than anyone else. Yet as these cars cannot be distinguished from better cars, they may be sold under asymmetric information when they would fetch a relatively high price.

In the case of insurance, the greater the risk, the more a client will pay for a policy, but the more it will cost to provide it. When loss is very likely, fair insurance provides little risk reduction and when administrative costs are taken into account, the premium may exceed willingness to pay. Under symmetric information, high risks would not insure and it would be inefficient for them to do so. High and low risks may be pooled under asymmetric information at a premium below the willingness to pay of the high-cost individuals, who are then inefficiently drawn into the market.

These examples of excessive trade are not attributable to advantageous selection, whereby the traders least preferred by the uninformed side of the market drop out as price rises. More exchange does then occur than under full information (de Meza and Webb, 1987, 2001), but in our settings, the informed parties most willing to trade are those least preferred by the uninformed parties, genuine adverse selection.

The essential requirement for the novel result of market over-expansion is that high willingness to pay (low willingness to accept) does not mean it is efficient to trade since costs may be even higher (value even lower), but under adverse selection these are the types that are keenest to be in the market. There are a variety of ways this configuration may occur. We illustrate in the canonical selection markets of insurance, credit and used cars.

Although adverse selection may involve more trade than under full information, the bad trades responsible cannot be eliminated by transaction taxes without also destroying the market. A subsidy, leading to further expansion, does then increase aggregate surplus. Other interventions such as bankruptcy penalties can eliminate

\footnotetext{
${ }^{1}$ We are grateful to a referee for the formulation that follows.

${ }^{2}$ In Akerlof, cars are perfect substitutes; owning two cars with half quality is as good as one car with full quality, so there is no car that is inefficient to own under full information.
} 
bad trades without displacing good trades.

Asymmetric information is sometimes the result of deliberate policy, for example when pricing based on protected characteristics is prohibited. The possibility of bad trades is then relevant in assessing the efficiency implications of the policy, though of course this is not the only consideration. Relatedly, the value of eliminating adverse selection through the provision of better information depends on whether bad trades would otherwise occur. Private decisions to screen may be mainly dissipative in which case screening should, if possible, be prohibited. If bad trades are a feature of equilibrium, private decisions to screen are more likely to be beneficial.

Although the possibility of market expansion under adverse selection does not seem to have been pointed out before, the setup in Bundorf, Levin and Mahoney (2012), henceforth BLM, contains relevant ingredients. Two health insurance policies are available in BLM and everyone must buy one or the other. For all consumers, willingness to pay for policy A exceeds that for policy B, but the difference may increase in consumer risk, in which case private and social surplus rank in opposite directions. ${ }^{3}$ The main theoretical result in BLM is that no premium pair achieves full efficiency (see also Glazer and McGuire, 2011, and Geruso, 2017). As BLM do not provide an analysis of equilibrium, they do not address the effect of adverse selection on the extent of the market, nor do they consider appropriate market interventions.

The next section provides the basic analysis. Policy implications follow. Finally, brief conclusions are drawn.

\section{The analysis in pictures}

\section{$2.1 \quad$ Insurance}

To make the point that adverse selection may expand the market, we adapt the useful graphical exposition of Einav, Finkelstein and Cullen (2010) and Einav and Finkelstein (2011). Two mechanisms that give rise to excessive inclusion are considered: 1. Loading factor; 2. Discretionary expenditure.

\section{Loading factor}

Each member of a population has wealth $W$, and may suffer financial loss $L$. The continuous and differentiable distribution function of loss probabilities is $F(p)$ with support $[\underline{p}, \bar{p}]$. We will sometimes refer to $q=1-F(p)$ as the number of those with

\footnotetext{
${ }^{3}$ Other papers with multiple policies include Saltzman (2021), Hendren et al. (2021) and Marone and Sabety (2021), but explicitly or implicitly make assumptions that preclude market expansion.
} 
loss probability above $p$. There is a common concave utility of wealth function, $U(\cdot)$. A single insurance policy that covers the loss is offered by risk-neutral competitive insurers. ${ }^{4}$ Willingness to pay (WTP) for the policy, $w \equiv w(q)$, satisfies

$$
(1-p) U(W)+p U(W-L)=U(W-w),
$$

yielding

$$
\frac{d w}{d p}=\frac{U(W)-U(W-L)}{U^{\prime}(W-w)}>0 .
$$

By (2), willingness to pay for insurance is increasing in $p$ and hence decreasing in $q$. When all buyers face the same premium, as under asymmetric information, it will be those with the highest loss probabilities that are insured with the better risks dropping out as the premium rises. Selection, is therefore adverse (from the perspective of insurance companies).

The insurer's expected cost of supplying a policy depends on the insured loss probability according to

$$
C=p\left(c_{1}+L\right)+c_{2},
$$

where $c_{1} \geq 0$ is claim processing cost, and $c_{2} \geq 0$ is the cost of issuing a policy. ${ }^{5}$

In Figures 1a and 1b, the vertical axis measures the insurance premium, $P$, and the cost of providing the contract. The horizontal axis is the quantity index, $q=1-F(p)$.

The expected cost of supplying a policy to the $q$ th highest $p$ type is

$$
\left(c_{1}+L\right) F^{-1}(1-q)+c_{2} \equiv M C(q),
$$

with the average cost of supplying the highest $q$ loss-probability policies,

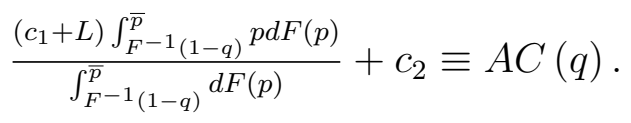

\footnotetext{
${ }^{4}$ As Einav and Finkelstein (2011) concede, the assumption of an exogeneous contract is a drawback. Rothschild and Stiglitz (1976) endogenize contracts for the adverse selection case, and de Meza and Webb (2001) for advantageous selection. Azevedo and Gottlieb (2017) provide an innovative multidimensional model of insurance with endogeneous contracts and a continuum of types with pooling in equilibrium. Geruso et al (2019) and Saltzman (2021) study adverse selection when a variety of policies are offered. Our results also apply in this context.

${ }^{5}$ These costs should include the hassle costs of the insured in claiming and applying for contracts (or else deducted from WTP). Administrative costs of insurers are often high. Examining individual insurance returns lodged with the then UK regulator, the FSA, claims management costs for nonlife lines of insurance are reported at between $8 \%$ and $12 \%$ of claims paid. See also KPMG (2011), which put the average loss ratio (net claims and claims expenses as a percentage of net earned premiums) for UK general insurance at $63 \%$. Total expenses (not just claim processing costs) are some $32 \%$ of income.
} 
As $p$ is lower at higher $q, M C(q)$ is declining in $q$, with $A C(q)$ likewise (linearity applies if the distribution of loss probabilities is uniform). Under full information, everyone for whom $w(q) \geq M C(q)$ is insured. With asymmetric information, sellers do not know individual probabilities, so everyone must be offered the same premium. Assuming Bertrand competition, equilibrium involves zero expected profit when all those with $w(q)$ above the equilibrium premium buy. In addition, no price deviation must increase the profit of an individual insurer. These requirements are satisfied at $q^{*}$, the highest $q$ for which $A C(q)=w(q)$, or at $q=1$ if $A C(1)<w(1)$. The market is active if $q^{*}>0$.

Figure $1 a$ shows the case of support $[0,1]$. The properties are as follows:

i) When administrative costs are zero, $w(q)=M C(q)=A C(q)$ at $q=0$ and at $q=1$, whilst due to risk aversion, $w(q)>M C(q)$ when $0<q<1{ }^{6}$ An active selection market requires $w(q)>A C(q)$ for some $0<q \leq 1$. As $w(q)$ is increasing in risk aversion but $A C(q)$ is independent of risk aversion, this condition can certainly be satisfied. An active insurance market then exists at the highest $q$ that satisfies $w(q)=A C(q)$.

ii) Introducing positive administrative costs raises $M C(q)$ and $A C(q)$. If these costs are not too great, $w(q)=A C(q)$ at a positive but lower $q$ than with no costs. The insurance market therefore remains active. At $q=0$, and in that vicinity, risk is minimal, so there will be a threshold below which $w(q)<M C(q)$. These are individuals who would not insure under full information but do so under asymmetric information.

Two distortions arise. In the interval $F G$ the cost of providing the contract is exceeded by willingness to pay for it, so these individuals would be insured under full information but are excluded under asymmetric information. This is the standard underinsurance of good types. In addition, $0 E$ bad risks are now insured that value the policy less than its cost, so would not be insured under full information. As WTP must be below $M C$ in the neighborhood of $p=1$, a region of inefficient trade must exist. It is ambiguous whether more policies are sold than under full information but, even if the number of policies remains the same or falls, the two sources of welfare loss remain. ${ }^{7}$

Figure $1 b$ presents a slightly different configuration that arises if $\bar{p}$ is sufficiently low. The equilibrium now involves all insured although, under full information, $0 E$

\footnotetext{
${ }^{6}$ There is a discontinuity at the extreme values of $q$.

${ }^{7}$ The positive correlation test of Chiappori and Salanie (2000) is satisfied. Those buying insurance are more likely to suffer a loss. Limits to this test for adverse selection are discussed in de Meza and Webb (2017), and Fang and Wu (2018).
} 
individuals would not be insured. More policies are definitely sold. ${ }^{8}$

The properties in $i$ ) and $i i$ ) yield the main result:

Proposition 1 An active adverse selection market generates negative surplus contracts if, at $\bar{p}$, administrative cost exceeds the risk premium, as must be true if $\bar{p}=1$. A sufficient condition for insurance to exceed the full-information level is that $\bar{p}<1$ and risk aversion is sufficient that all are insured.

To illustrate these results, consider the one-sided triangular distribution $f(p)=$ $2(\bar{p}-p) /(\bar{p}-p)^{2}$ and the CARA utility function $1-e^{-R W}$. Administrative costs are $r \%$ of expected payouts. Setting $W=100, L=80, r=0.25, R=0.035, \bar{p}=0.8$, $\underline{p}=0.2 .^{9}$ The equilibrium is of the form in Figure 1b. Everyone is insured under asymmetric information (the premium is based on the average loss probability of 0.4 , but even those with $p=0.2$ are sufficiently risk averse to want a policy on these terms). Due to the administrative cost, those with $p>0.71$ would not be insured under full information. There is adverse selection in that WTP is monotonically increasing in $p$, but the result is overexpansion of the market.

\section{[FIGURE 1 HERE]}

\section{Discretionary expenditure}

The overinsurance possibility depends on the high loss-probability types not insuring under full information. Loading factors are not the only way to generate Figures $1 a$ and $1 b$.

Consider a medical condition that lowers the concave utility function from $U(W)$ to $u(W)$, where $W$ is initial wealth. There is a medical treatment that $\operatorname{costs} M$ that restores the utility function to the well state. The probability of the condition is $p$. As the individual is risk averse, when the expenditure is to be made in the event of the condition occurring, it will be financed through actuarially fair insurance, if available. Insurance will therefore be taken rather than not making the medical expenditure if

$$
D=U(W-p M)-[(1-p) U(W)+p u(W)]>0,
$$

\footnotetext{
${ }^{8}$ To analyze the choice between two policies, let the vertical axis represent cost and price differences of the better policy relative to the worse, as in Layton (2017) and Layton et al. (2017). The better policy is then characterized by adverse selection and the worse by advantageous selection. The better policy may now overexpand.

${ }^{9}$ In the empirical range, see e.g. Paravasini et al. (2017).
} 
with

$$
\frac{d D}{d p}=-U^{\prime}(W-p M) M+[U(W)-u(W)]
$$

and

$$
\frac{d^{2} D}{d p^{2}}=U^{\prime \prime}(W-p M) M^{2}<0 .
$$

As the probability of illness increases, the advantage of insurance decreases and may turn negative. Insurance is just too expensive when loss probability is high. For example, if $U(W)=1-e^{-R W}, u(W)=0.8 U(W), R=0.035, W=100, M=8$, the crossover illness probability is 0.525 .

Although WTP for insurance increases in $p$ (the criterion for adverse selection under asymmetric information), it may not exceed the cost when $p$ is high, leading to overinsurance under asymmetric information.

\subsection{Credit}

In the classic credit market analysis of Stiglitz and Weiss (1981), each of a collection of entrepreneurs is endowed with a single indivisible project that requires external funding to proceed. Gross return is binary. Failure yields no revenue and occurs with probability $p$, whilst success yields output $y$. Initially, all agents are risk neutral. The distribution function is $F(p)$, with quantity index $q=1-F(p)$.

Projects differ by mean preserving spreads, that is $p$ and $y$ satisfy

$$
(1-p) y=\bar{y}
$$

The highest repayment a borrower will accept, the willingness to borrow, $w \equiv$ $w(q)$, satisfies

$$
(1-p)(y-w)=u,
$$

where $u$ is the opportunity cost of running the project, the same for all, implying willingness to borrow is

$$
w(q)=\frac{\bar{y}-u}{1-p(q)} .
$$

The maximum acceptable repayment in (10) is increasing in the borrower's $p$, project risk.

In determining lenders' required repayment, for simplicity, let the safe interest rate be zero. Also, the supply of funds to lenders collectively is perfectly elastic, so rationing cannot arise. Under full information, the breakeven repayment on a loan, the marginal repayment to a borrower known to have loss probability $p$ is

$$
\frac{L}{1-p(q)} \equiv M R(q)
$$


where $L$ is the loan advanced. Low-risk projects break even at lower interest rates, therefore (10) and (11) imply this is an adverse-selection market. At high interest rates the low risk, those most profitable to lend to, drop out.

The difference between the highest repayment a type- $p$ borrower will accept and the breakeven repayment is

$$
w-M R(q)=\frac{\bar{y}-u-L}{1-p(q)},
$$

where the numerator is the net gain from each project. Under full information, loans are made on all projects for which $w>M R(q)$. From (12), If anyone gets a loan, all do.

Under asymmetric information, lenders only know the population distribution of $p$. If loans are made to the $q$-highest loss types, the repayment required for the lender to breakeven overall is

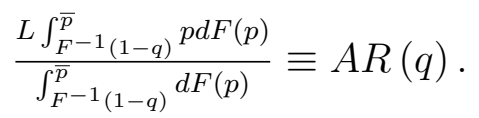

Figure $2 a$ shows the three functions under risk neutrality assuming $\bar{y}-u-L>0$, so lending is efficient. The breakeven repayment is indicated with $r^{*}$. It then follows that $w>M R(q)$ for all $q$, so under full information all projects are funded. Under asymmetric information, loan repayment requires $w=A R(q)$, so only the $0 E$ riskiest projects are funded. This is the familiar lemons result: inefficient market shrinkage under asymmetric information. ${ }^{10}$

Now introduce risk aversion. Every entrepreneur has the concave utility of income function $U(\cdot)$. It is now ambiguous whether at a given interest rate it is better to have a riskier project. The entrepreneur's expected income is higher, but the extra risk lowers their expected utility. If risk aversion is high, greater risk may lower expected utility resulting in advantageous selection. The expected utility of a $p$-type borrower is $(1-p) U(y-w)$, which in conjunction with (8), implies that adverse selection, $d w / d p>0$, holds iff

$$
\frac{U^{\prime}(y-w) y}{U(y-w)}>1
$$

Risk aversion lowers the expected utility of active entrepreneurs and therefore the highest repayment they will accept, shifting the $r$ schedule down. As the effect is greatest for the riskiest projects, Figure $2 b$ is possible. The asymmetric equilibrium

\footnotetext{
${ }^{10}$ If $A R(q)$ bisects $M R(q)$ and $w$, there is complete market collapse.

As each project contributes $\bar{y}-u-L$ to total welfare, the gain from a loan is not the vertical difference $w-M R(q)$.
} 
remains that all get loans, but now the riskiest $0 F$ individuals are excluded under full information. ${ }^{11}$

Proposition 2 Adding risk aversion to the Stiglitz-Weiss model may generate advantageous selection. Even if adverse selection remains, there may be more lending under asymmetric than symmetric information.

[FIGURE 2 HERE]

\section{$2.3 \quad$ Used cars}

This is the original Akerlof setting. A mass of individuals each own a single car. The quality of cars is distributed according to $F(Q)$, with higher $Q$ better quality. In a simplified representation, owners have identical preferences. Their willingness to accept for a car of known quality is $w \equiv w(Q)$, increasing in $Q$. More cars are therefore put on the market when price is higher and average quality increases. Under asymmetric information, adverse selection therefore applies. The willingness to pay (marginal valuation) of the identical risk-neutral potential buyers for a car with quality $Q$ is $M V(Q)$, increasing in $Q$. Willingness to pay for a lottery of a car (average valuation), selected at random from all those with quality at or below $Q$, is

$$
\frac{\int_{0}^{Q} M V(Q) d F(Q)}{\int_{0}^{Q} d F(Q)} \equiv A V(Q)
$$

The measure of owners is one and of non-owners is $N$ (in the previous applications there are infinitely many uninformed agents). Two cases arise according to whether there are more buyers than sellers, that is: $1 . N>1 ; 2 . N<1$.

\section{1. $N>1$}

Figure $3 a$ shows the standard lemons case. The quantity of cars marketed, $q=$ $1-F(Q)$, is on the horizontal axis. Adverse selection implies that the more cars offered by owners, the higher the quality so the higher the price required to elicit the greater supply. Thus, the buyer's valuation, $w(q)$, of the $q$ th best car is increasing

\footnotetext{
${ }^{11}$ The essential property is that at high $y, w-M R(q)<0$, but at lower $y, w-M R(q)>0$. This can be confirmed by example. Let $U(m)=0.1 m-0.1 m^{2}$. At fixed repayment expected utility is increasing in $y$ and with $L=1.8$ and $u=0.014$, between $y=2.8$ and $y=3.2$, the inequality reversal occurs.
} 
in $q$, as is $M V(q)$ and the buyer valuation of a lottery of the $q$ worst cars, $A V(q)$. Under full information, all cars are traded as for every car, $M V(q)>w$. As there are more buyers than sellers, and buyers are free to choose any car, prices must be bid up till buyers obtain zero surplus whichever car is bought. The price of quality $Q$ is given by $M V(Q)$ and every seller receives in excess of their $w(Q)$.

Under asymmetric information, the quality of the marginal car traded satisfies $A V(Q)=w(Q)$, so only the worst $0 A$ cars are traded. Transaction volume has fallen.

In Figure 3b, within the interval $0 B, M V(Q)<w(Q)$, so these cars are not traded under full information. Amongst reasons for the existence of this interval is transaction costs independent of quality. Under asymmetric information, even for the best car $A V(Q)>w(Q)$, so all cars are traded, with price bid up to $P^{*}$.

\section{2. $N<1$}

In Figure 3a, all $N$ buyers obtain cars under full information. If $M V(Q)-w(Q)$ is increasing in quality, it will be the best cars that are sold. Buyers must again obtain equal surplus whichever car is bought, whereas the seller of the Nth best car must get zero surplus or they will be undercut by worse cars.

Under asymmetric information there is a single price and it is the $N$ worst cars that are sold. If $0 A>N$, the price equals the willingness to sell of the $N t h$ worst car. The transaction volume is the same as under full information, but as different cars are traded, efficiency is lower. If $0 A<N$, only the worst $0 A$ cars are sold.

In the case of Figure $3 b$, under full information, the best $\min (N, 1-0 B)$ cars are traded but, under asymmetric information, it is the worst $N$ cars that are traded at price $w(N)$, so if $1-0 B<N$, trade is higher under adverse selection.

Proposition 3 In a used car market characterized by adverse selection, transactions may be higher than under full information but, even if not, it will be the wrong cars that are traded.

Market expansion requires that some low-quality cars are not traded under full information. It is not just transaction costs that may have this effect. Owners of impaired items may have learned to live with the problem whereas buyers are apprehensive. Also, behavioral effects may come into play such as the "disposition effect", according to which, owners are reluctant to take an exceptional financial loss on the item. ${ }^{12}$ Most simply, some owners of lower-quality cars may have a relative preference for them.

\footnotetext{
${ }^{12}$ For example, Genesove and Mayer (2001) find that, for housesellers, willingness to accept is increasing in purchase price.
} 
[FIGURE 3 HERE]

\section{Some policy implications}

When adverse selection expands the market relative to full information, the extra trade is dysfunctional because it is valued below the cost of provision. As this "bad" trade has the highest WTP, it cannot be eliminated by taxing transactions without resulting in market closure. A less prohibitive tax drives out marginal types for whom WTP is low, but the cost of provision is even lower. The standard recommendation to subsidize transactions in the presence of adverse selection therefore applies, enlarging the market still further. Whereas the bad trades increase the deadweight cost of asymmetric information, unlike the cases considered by Einav, Finkelstein and Cullen (2010), simple transaction taxes and subsidies cannot achieve full efficiency.

Taxing or subsidizing transactions is not the only intervention possible short of changing information provision. For example, regulation that affects bankruptcy cost hits high-risk trade by more than low-risk. ${ }^{13}$ This makes it possible to eliminate bad trades whilst preserving good trades. As bankruptcy penalties cannot normally be financial, real costs are involved but there may be a net efficiency gain, especially if bankruptcy penalties are used in conjunction with transaction subsidies.

Asymmetric information may be the deliberate creation of regulation that prohibits the use in pricing of informative protected characteristics, such as race or sex. Measuring the efficiency cost, if any, of such policies requires evaluating both crowdout and crowd-in effects. In other cases, screening is possible, but at a cost. Whether private decisions to screen are in the social interest is then an open question. As is well known, screening is typically regressive, redistributing from the less able to the more able, and in burning up resources is also inefficient. Crowding in increases the value of screening. ${ }^{14}$ The benefit of market shrinkage is generally overlooked, but may be important.

\section{Conclusion}

In the standard analysis of adverse selection, all realized trades generate positive surplus. The efficiency problem is that some positive-surplus trades do not happen.

\footnotetext{
${ }^{13}$ Bankruptcy policy is not ony relevant to credit markets. As Mahoney (2015) documents, bankruptcy provisions influence willingness to pay for health insurance.

${ }^{14}$ As can be demonstrated by application of the competitive credit-market screening model of de Meza and Webb (1988).
} 
This paper shows that adverse selection markets may also generate trades that would not happen under full information, a further source of inefficiency. The key to this occurring is that not every trade in which the informed party has high willingness to pay or low willingness to accept would happen under full information. Why this may be the case depends on the context and three illustrations are provided here.

The usual tests for adverse selection do not reveal the presence of disadvantageous trade. It remains true that under asymmetric information the insured have higher loss probabilities than the uninsured, so the positive correlation test of Chiappori and Salanie (2000) for adverse selection will be passed. Exogenous price variation is used by Einav, Finkelstein and Cullen (2010) and others to estimate how demand changes affect the cost of provision. If complete demand and cost functions are estimated, disadvantageous trade can in principle be identified. Normally, it is only price changes in the region of equilibrium that are observed, ruling out identification of disadvantageous trade which typically arises for non-marginal buyers or sellers.

The most promising test method is perhaps to look at the effects of varying the provision of information. In the standard analysis, better information adds some trade but loses none. In many cases this test is unlikely to be met. Consider,for example, the commercial offer of Big Data Scoring:

"We develop and deploy custom scoring models that combine a lender's internal data with thousands of pieces of external data such as location based information, web search results, behavioural tracking, device technical details, mobile app data and much more. This enables lenders to accurately predict borrower payment behaviour, helping them make informed and more profitable credit decisions in real time."

The service being supplied almost certainly involves the elimination of unprofitable loans. This is not necessarily in the social interest, but the Big Data effect does indicate that the standard analysis of adverse selection that rules out the possibility of dysfunctional market expansion is a special case that is not obviously realistic.

\section{References}

Akerlof, G. (1970). The Market for Lemons: Quality Uncertainty and the Market Mechanism. Quarterly Journal of Economics, 84, 488-500.

Azevedo, E. and Gottlieb, D. (2017). Perfect Competition in Markets with Adverse Selection, Econometrica, 85, 67-105.

Bundorf, M., Levin, J. and Mahoney, N. (2012). Pricing and Welfare in Health Plan Choice. American Economic Review, 102, 3214-3248. 
Chiappori, P. and Salanie, B. (2000). Testing for Asymmetric Information in Insurance Markets. Journal of Political Economy, 108, 56-78.

de Meza, D. and Webb, D. (1987). Too Much Investment: A Problem of Asymmetric Information, Quarterly Journal of Economics, 102, 281-292.

de Meza, D. and Webb, D. (1988). Credit Market Efficiency and Tax Policy in the Presence of Screening Costs. Journal of Public Economics, 36, 1-22.

de Meza, D. and Webb, D. (2001). Advantageous Selection in Insurance Markets, RAND Journal of Economics, 32, 249-262.

de Meza, D. and Webb, D. (2017). False Diagnoses: Pitfalls of Testing for Asymmetric Information in Insurance Markets, Economic Journal, 127, 2358-2377.

Einav, L. and Finkelstein, A. (2011). Selection in Insurance Markets: Theory and Empirics in Pictures. Journal of Economic Perspectives, 25, 115-138.

Einav, L., Finkelstein, A. and Cullen, M. (2010). Estimating Welfare in Insurance Markets using Variation in Prices. Quarterly Journal of Economics, 125, 877-921.

Fang, H. and Wu, Z. (2018). Multidimensional Private Information, Market Structure, and Insurance Markets, RAND Journal of Economics, 49, 751-787.

Genesove, D. and Mayer, C. (2001). Loss Aversion and Seller Behavior: Evidence from the Housing Market. Quarterly Journal of Economics, 116, 1233-1260.

Geruso, M. (2017). Demand heterogeneity in insurance markets: Implications for equity and efficiency. Quantitative Economics, 8, 929-975.

Geruso, M., Layton, T, McCormack, G, and Shepard, M. (2021). The Two Margin Problem in Insurance Markets. Review of Economics and Statistics (forthcoming).

Glazer, J. and McGuire, T. (2011). Gold and Silver Health Plans: Accommodating Demand Heterogeneity in Managed Competition. Journal of Health Economics, 30, 1011-1019.

Hendren, N., Landais, C. and Spinnewijn, J. (2021). Choice in Insurance Markets: A Pigouvian Approach to Social Insurance Design. Annual Review of Economics, 13, 457-486. 
KPMG (2011). General Insurance: Performance Benchmarking Survey. Available at: kpmg.com/uk/en/issuesandinsights/articlespublications/pages/generalinsurance2011.aspx

Layton, T. (2017). Imperfect Risk Adjustment, Risk Preferences, and Sorting in Competitive Health Insurance Markets. Journal of Health Economics, 56, 259-280.

Layton, T., Ellis, R., McGuire, T. and Van Kleef, R. (2017). Measuring Efficiency of Health Plan Payment Systems in Managed Competition Health Insurance Markets. Journal of Health Economics, 56, 237-255.

Mahoney, N. (2015). Bankruptcy as Implicit Health Insurance. American Economic Review, 105, 710-746.

Marone, V. and Sabety, A. (2021). Should There be Vertical Choice in Health Insurance Markets? NBER wp 28779.

Paravisini, D., Rappoport, V. and Ravina, E. (2017). Risk Aversion and Wealth: Evidence from Person-to-Person Lending Portfolios, Management Science, 63, 279297.

Saltzman, E. (2021). Managing Adverse Selection: Underinsurance vs. Underenrollment. RAND Journal of Economics, 52, 359-381

Rothschild, M. and Stiglitz, J. (1976). Equilibrium in Competitive Insurance Markets: An Essay in the Economics of Imperfect Information, Quarterly Journal of Economics, 90, 629-650.

Stiglitz, J. and Weiss, A. (1981). Credit Rationing in Markets with Imperfect Information, American Economic Review, 71, 393-410. 